\title{
O giz, o linóleo e a parede \\ - breves considerações sobre uma cartografia do salto em $A$ parede, de Elfriede Jelinek
}

ANABELA MENDES

\begin{abstract}
"Falling from our wall" invokes a collective denomination of an object that serves everyone, basically the female figures in the play and us. It appears as an object that gains affection from them because it affects them, with which they care, of which they use beyond measure to reach an end, which they reject when they don't understand it. But The Wall also invokes the shattering of women, of any woman who sees herself reduced to image, whose reification cannot be freed and whose detachment as an image that time consecrates is suspended by inversion of function.
\end{abstract}

ESFACELAMENTO / O SANGUE SEMPRE O SANGUE / INJUNÇÃO DA TEMPORALIDADE / MUTABILIDADE / CORALIDADE / O PESO DO ABANDONO

$O$ respeito pressupõe um olhar distanciado, um pathos da distância. Trata-se de uma atitude que hoje é substituída por um olhar sem distância, o olhar típico do espetáculo. [...] É a distância que distingue o respectare do spectare.

BYUNG-CHUL HAN

\section{ENUMERAÇÃO}

Encontro-me no patamar menos cinco. Ou será antes o menos vinte e cinco? Não sei como aqui cheguei. Talvez vinda de uma cena de esquartejamento de um ser, na qual não participei porque se me encheram de sangue os olhos. Assim salpicados a curtos intervalos, deixei de ver e fiquei imóvel. Quem esquartejava? Seres em raiva? Tratava-se de uma vingança? Uma muito ancestral?

Também poderia aqui ter chegado vinda através da escrita de alguém, talvez de alguém com um gesto competitivo que propiciaria uma cegueira infinda. Seria ela maléfica? Há cegueiras e cegueiras. Não ver 
não significa que se queira mesmo ver. Eu fui impedida de ver pelo sangue do ser esquartejado. Mas será que eu queria mesmo ver? E a querer teria participado nesse hediondo acto?

Ao longo do caminho que até aqui me trouxe, e que não sei dizer quanto tempo durou, tive inesperados (ou seriam eles esperados?) encontros com paredes e muros que me tentaram despedaçar. Já quase se me varreram da memória essas experiências. Mas se elas se tivessem eclipsado mesmo, provavelmente não estaria aqui no patamar menos cinco. Será que estou no menos vinte e cinco? Vinte patamares de diferença seriam motivo para outras enumerações. E eu estou aqui para contar histórias com paredes, ainda que elas desconheçam o meu propósito.

Deste patamar onde me encontro, sem bem saber qual ele é, e talvez isso afinal não seja assim tão importante, e também por essa razão, de ora avante, não mais a ele me referirei. Vai-te patamar! Não obscureças o meu discernimento! Estou a pensar colocar o patamar (ainda mais uma vez!) numa descomunal gamela, juntamente com o ser esquartejado, que uma vingança antiga e não terminada faz viver e reviver sem apelo nem agravo. Apenas um breve esclarecimento: a gamela que escolhi, além de ser de grandes proporções, para bem alojar esse ser esquartejado (são sempre enormes também!) e a plataforma (outra vez ainda!) aonde cheguei sem saber como, é feita à mão e provém de árvore da mesma família linguística - a gameleira, talvez uma ficus insipida.

\section{O QUE EU QUERO É DISTÂNCIA}

Porquê distância? Que quer isso dizer? Criar espaço onde ele se recusa a existir? Como se conduzem memórias no espaço da distância e à distância? Como se apagam umas e se reavivam outras? Quais são os intervalos que nos escapam? O que excluímos nós do mundo que nos exclui? Porque queremos continuar a ser bárbaros? Porque concedemos à violência física e anímica aquele único posto de combate, sem o qual, parece, não somos capazes de enfrentar a tragicidade dos nossos destinos? É a propósito de tudo isto e, quem sabe, de muitas e variadas coisas mais que A Parede, de Elfriede Jelinek nos invectiva.

Destaquemo-la do conjunto de cinco dramatículos e um posfácio que constituem a obra cénica A Morte a Donzela (2004). A Parede vem em quinto lugar. Mas o seu espaço traz o explícito selo do mitológico que transporta consigo cultura e se dá em transmissão. E essa transmissão pressupõe que continuemos a olhar para trás tanto quanto na direcção oposta, criando assim um tipo de distância que nos implique com verdade. Como decidir para onde olhar com mais intensidade? Faz parte desta ordem o sangue do esquartejado que outros seres reclamam de forma satisfatória como paga por suas dores e que por vingança decidem que escorrerá violenta e eternamente. Será tudo isto por anseio de poder?

O esquartejamento de um corpo é um acto contranatura, mesmo que esse corpo seja o de um bode. $E$ ao bode dá-se um nome: estar em vez de. O rito sacrificial teria sido menos proveitoso se entre as castradoras - em Jelinek estas são mulheres com músculo, mas tão frágeis como outras quaisquer -, portanto, entre as castradoras e a vítima tivesse havido uma parede? E se esta lá estivesse e ninguém a tivesse visto? E se ela for transparente? E se ela, salvaguardadas as devidas distâncias, se tornar num objecto múltiplo e funcional, uma espécie de robô de cozinha para qualquer eventualidade?

Tanta desumanização contra um corpo pressupõe excesso de dor no visado, em quem pratica o acto (uma inexplicável dor mas muito intuitiva), e também naqueles que se encontram em redor paralisados pelo sangue infame. Estar em vez de, a expressão com que aqui se nomeia o bode, não isenta ninguém, nem homens nem mulheres, deste processo de tão grande conflitualidade e perda que sempre de longe nos chega e sempre em actualização.

Aqui se recorda da Odisseia de Homero, o Canto XI, versos 146-149, onde encontramos Tirésias em diálogo com Ulisses: «Dir-te-ei uma palavra fácil, que porei no teu espírito./ Àquele, dentre os mortos que partiram, que permitires/ aproximar-se do sangue, esse falar-te-á com verdade;/ porém quem recusares de novo se retirará. $\rangle^{1}$

Estas foram as palavras inspiradoras, que Elfriede Jelinek tomou como suas, dando voz à criatura num registo de abafamento, como se o eterno retorno, agindo sob a distância especular, amado e citado à sua maneira, estivesse a ser dito e se atravessasse no que já antes fora dito de tantas maneiras:

«É fácil o que vocês me perguntaram mas eu vou dizê-lo na mesma. São as frases mais terríveis que alguma vez foram ditas. É por isso que expressamente peço silêncio, porque eu não conseguiria dizê-las outra vez: aquele a quem vocês agora permitem, o morto separado, de se

Homero, Odisseia, trad. Frederico Lourenço, Lisboa, Livros Cotovia, 2003, p. 18 
aproximar do sangue, esse contar-vos-á a verdade. Mas aquele a quem vedardes esse acesso, esse regressará no mais profundo silêncio. ${\aleph^{2}}^{2}$ Está instalada a dúvida entre verdade e conhecimento e para tal contribuem as diversas formas de apresentação/representação que dão molde à parede e que a ela atribuem protagonização.

E aqui se replica a famosa pintura inspirada na verdade de Tirésias, agora de Johann Heinrich Füssli (1741-1825), pintor suíço que, ao modo chiaroscuro de raiz italiana, reconverte as palavras proferidas pelo vidente num plácido contraste dramático que o mundo dos mortos instaura como resposta ao que resposta ainda não é. Jelinek também sabe de imagens como esta que se perguntam se para a dor e a morte há antídoto.

É no início do dramatículo que a voz autoral se expressa através de uma metodologia impositiva que lhe dá o direito de intervir na capacidade de criação de todo e qualquer encenador. ${ }^{3}$ Assim se refere na segunda didascália de A Parede: «Desta vez, porém, o Senhor Director, a Senhora Directora devem, pelo menos, nas suas grandes linhas, respeitar as indicações cénicas que eu determinei, pois desta vez elas fazem parte do texto. Lamento imenso.» ${ }^{4}$

2 Para efeito de citação e por se tratar de um instrumento de trabalho anotado e que corresponde à versão de palco trabalhada com Alexandre Pieroni Calado (encenador) e Paula Garcia (actriz), recorro à minha tradução da peça em dactiloscrito e de ora avante sempre a ele. Dactiloscrito, p. 29.

Distorial de edição desta obra criou para o público leitor um fenómeno pouco comum na sabendo-se que estes são editados com pouca sistematicidade. A primeira em particular, peças de Jelinek surgiu por desejo meu, apresentado a Alexandre Pieroni Calado e à Artes \& peças de Jelinek surgiu por desejo meu, apresentado a Alexandre Pieroni Calado è à Artes \&
Engenhos. Razões académicas mas também sentimentais levaram-me a conceber, com o apoio da designer gráfica Isabel Espinheira, uma muito pequena quantidade de exemplares de distribuição gratuita e em edição numerada à mão. Esta edição pode ser consultada na Biblioteca Nacional de Portugal, onde repousa disponivel. Os volumes oficialmente editados encontram-se nas mãos de familiares e amigos - Elfriede Jelinek, A Morte e a Donzela - Dramas de Princesas, tradução e nota introdutória - Onde começa e acaba uma princesa? - de Anabela Mendes, Lisboa: Artes \& Engenhos (edição de 25 exemplares numerados), 2018, p. 69. Apenas a título de exemplo se refere a página desta edição, acima mencionada neste ensaio.

Desde que abraçou o projecto Europa, de que esta obra conjunta faz parte, Alexandre Pieroni em edição regular. Tal veio a acontecer sob a chancela do editor Carlos da Veica Ferreira e teodolito - Elfriede Jelinek, A Morte e a Donzela - Dramas de Princesas, tradução e nota introdutória Onde começam e acabam as princesas? de Anabela Mendes, Lisboa, teodolito/edições afrontamento, 2019, p. 105. Refere-se de novo a título de exemplo a página citada.

3 A este respeito, gostaria de salientar a sempre refrescada polémica em torno do teatro pós- dramático, que confunde muitos dos estudiosos da obra de Jelinek e aos quais a autora responde exactamente neste dramaticulo tornando audivel a sua voz de autora textual pela qual
pede respeito. Ver a este propósito Karen Jürs-Munby (2009), The Resistant Text in Postdramatic Theatre: Performing Elfriede Jelinek's Sprachflächen [Superfícies de linguagem], Performance Research: A Journal of the Performing Arts, 2010, p. 47.

Ver ainda Hanna Klessinger 2006. Postdramatik: Transformationen des epischen Theaters bei Peter Handke, Heiner Müller, Elfriede Jelinek und Rainald Goetz, Edition De Gruyter: Berlin, New York, pp. 177-18

4 Dactiloscrito, p. 1
A levarmos à letra estas palavras, teremos de considerar que o que é subtexto na peça passa também a ser texto, e que a montagem cénica estabelecida a partir de algumas das didascálias não produz coincidência com material formalmente citado mas antes aludido. Exemplifiquemos:

No cume do rochedo está sentada uma criatura completamente enrolada em faixas, incluindo o rosto. Junto a ela há um bastão de ski pousado ao seu lado (ou dois bastões do tipo em uso para caminhadas), e ela usa óculos de sol muito escuros e na moda. [...] A criatura fala, mal se compreende o que ela diz, porque todo o seu rosto está envolto por faixas muito apertadas. ${ }^{5}$

Quem poderá ser esta criatura? Tirésias, que interpela Ulisses nas imediações do Hades? Um Tirésias remoçado mas que se quer emudecido? Deixou de ser avisado o seu conselho aos vivos? Haverá ainda mortos a quem seja permitido dizer a verdade? Quanto sangue continuará a correr?

Para quem visite a homepage (página principal) de Jelinek para contacto directo com o texto de $A$ Parede, aí encontrará esta imagem na qual o navegador laureado contempla do alto do rochedo uma cena de bacanal. Um Hades apetitoso, pois os mortos também têm direito a uma certa vida. As suas sombras, porém, mostram-se emparedadas entre uma ponte natural e o rochedo que as projecta.

\section{ENTRE COREOGRAFIA E CARTOGRAFIA}

São elas que, com o pau de giz entre os dedos, inscrevem sobre o linóleo as rotas que irão percorrer. Sabem-nas de cor, mas, à cautela, um desenho no chão é uma ajuda para os olhos de quem se lança no espaço em confronto com a parede. Tirésias enfaixado quase se esfuma entre os defuntos. A sua voz, ainda presente, produz enigmas. Elas estão ali para uma dança: a da morte em velocidades e ritmos vários, amortalhadas em vida. Elas? Sim, a Inge, a Sylvia, a Marlen/Therese, todas regressadas do submundo onde prosseguem os bacanais. Dito de outro modo: elas propagam-se em ondas num autêntico frenesi, multiplicam-se, fazem-se e refazem-se, desfazem-se atrás e à frente da parede, trepam por ela acima, deixam-se cair, fazem flick-flacks, jogam às decapitações, experimentam o fogão a gás na dimensão de um triplo emparedamento,

5 Dactiloscrito, p. 29. 
interrogam-se sobre a transparência ou sobre a inexistência da parede e através dela ensaiam o espelhamento e nela se introduzem em busca de descanso e de silêncio.

Elas representam-se e representam-nos na qualidade de mulier faber mas também de mulier figurans. ${ }^{6}$ Em ambos os registos, perpassa uma fatalidade própria do ser-se mulher. $\mathrm{O}$ que nos transmitem é o resultado de quem se move sobre terreno incerto numa permanente incompletude e insatisfação.

A duplicidade e a variabilidade dos seus comportamentos e atitudes, das ponderações amargas e ácidas com que nos confrontam, decorre de permanente agitação diluída ou a produzir-se em representação que não permitem o destrinçar minucioso de traços de personalidade nem a construção acentuada de perfil individual. Assim sendo, é na criação de movimento e acção que se configura o acto de representar que nos surge associado a um sentimento de irmandade que percorre a nomeação de Inge e Sylvia e menos de Marlen/Therese. A desavença pela parede e em torno dela torna-se produto de questionação do pensamento que se quer feita de viva voz. No fundo, a mulher que se figura e que figura, que cria representação, são todas as vozes intervenientes e as ausentes numa polifonia indestrinça.

Os corpos moventes e dançantes propõem-se a uma coreografia cartografada ao mesmo tempo no espaço mental e físico. Entre um Paraíso nunca alcançado e um assegurado Tártaro, porém, projectam-se todas as inversões e deformações sob cálculo e medição de uma visualidade que se esgota na próxima vontade de mudança.

A enunciação quase não tem marca de nomeação, a não ser na recuperada voz autoral, que opta por determinar o que a outros deveria pertencer. O discurso produz-se na consagração dos espaços que a mancha gráfica disponibiliza. Só assim se percebe quem diz o quê. Um parágrafo abre em contra-argumento o que foi fechado nos parágrafos anteriores, mas que em boa verdade pode conduzir a um combate de esgrima um pouco mais adiante e assim sucessivamente. Na criação deste desenho multifacetado, embora de ordenação visual em repetição, estreita-se o

6 Designação inspirada na formulação homo figurans que corresponde à importância atribuída e prioritária de representar sobre agir. No presente contexto, produz-se transporte para o género feminino, considerando, no entanto, que o efeito da representacão não tem de escolher género feminino, considerando, no entanto, que o efelto da representaçăo naão tem de escolher
género. A expressão está trabalhada em Eugenio Turri no ensaio $A$ Paisagem como Teatro - Do território vivido ao território representado, in Adriana Veríssimo Serrão (coord.), Filosofia da paisagem. Uma Antologia, Lisboa: Centro de Filosofia da Universidade de Lisboa, 2011, pp. 169-184 , p. 169. pensamento a contrapelo sempre fluido e abundante. Prepara-se a cartografia do salto.

A vocação das vozes é criar intermitência entre cultura (culturas) e barbárie, e é para isso que serve a parede como constante intermedialidade e que reflecte de inúmeras maneiras o exercício cruel a que se sujeitam as vozes em seres despedaçados e despedaçadores.

Na escrita fizemos juízos de valor, uma loucura, um processo, uma fixação de nós próprias. Mas, porra, voltámos a cair da nossa parede. Antes de termos chegado lá acima. Antes mesmo de termos podido fechar um matrimónio ou a porta. Aliás, também nada fechámos. Porque nada começámos. Esquecemo-nos completamente da porta da rua. Alguém acabou de nos pendurar na parede e agora estamos outra vez em baixo. A parede já está feita em estilhaços por sobre ela tentarmos pendurar as nossas imagens. ${ }^{7}$

«Cair da nossa parede» invoca uma denominação colectiva de um objecto que a todos serve (às figuras femininas da peça e a nós), um objecto que ganha afecto delas porque as afecta, com o qual elas se preocupam, do qual se servem desmedidamente para alcançarem um fim, que rejeitam quando o não entendem. Mas a parede invoca ainda por inversão de função o estilhaçamento da mulher, de qualquer mulher que se vê reduzida a imagem, e de cuja reificação não se consegue libertar e de cujo desprendimento como imagem que o tempo consagra se vê suspensa.

$O$ gesto de se fazer pendurar numa parede pela imagem representa, a meu ver, um processo substituto, com o seu quê de ornamental e sem encarceramento definitivo a não ser pela interferência de outrem. A imagem pendurada prolonga e engendra afecção e pensamento. Uma parede «já feita em estilhaços» retira discursiva e visualmente a possibilidade de se criar analogia. A alternativa à imagem pendurada não chega a surgir neste momento da peça. Pendurar-se com todo um corpo e para sempre é uma ideia por enquanto não equacionada e substituída por uma parede invisível $^{8}$, que nessa condição permite a continuidade da vida, sem que se fique preso, embora persista o caos, a dor, a cólera, a raiva e o abandono.

Dactiloscrito, p. 3

8 Referência ao romance de Marlene Haushofer Die Wand (A Parede). 
Segue-se no âmbito textual a parede engolidora que aparece como variante de uma boceta gigantesca («uma parede com uma racha»)9), pronta a desempenhar uma força múltipla implosiva e explosiva, uma força de cariz demoníaco, criando movimento contrário sempre em sintonia ou em sequência. Ser-se engolida pela racha da parede não pressupõe apenas que exista essa abertura à vista e disponível, mas que exista um movimento na sua direcção, um derradeiro e inquietante instante em que desaparecer seja simultaneamente desejo libertador de todo um corpo que antevê assim o seu fim e desse modo se pacifica talvez para sempre. Tal não é exactamente o sentido da passagem em comentário, embora ele seja aflorado, uma vez que a discussão à volta da parede é isso mesmo, põe em questão, introduz no discurso diversas possibilidades, cria diferentes cenários: a parede e a sua racha dão lugar a uma efectiva parede de palavras, sem que a mencionada abertura continue a ser mencionada ou sobre ela sejam tecidos quaisquer juízos de valor. O que importa reter é a condição de jogo representativo que se sobrepõe a acções invocadas e logo contrariadas ou abandonadas por negação ou derivação. A parede passa a ser um objecto (será que materializável enquanto unidade última?) que recebe sucessivas invectivações da parte de vozes insurrectas, a maior parte das vezes sem explícito nome anunciado, a não ser nas didascálias tornadas texto de representação e vozes, essas desmedidamente conscientes de processos do específico aniquilamento dos corpos a que pertencem.

A talentosa e portentosa escrita de Jelinek, na sua própria designação - Sprachflächen (superfícies ou planos de linguagem) - propõem deriva num permanente exercício de montagem, afeiçoamento a ideias opostas e paradoxais: «Mas a parede continua a não ser uma coisa concreta. Ela é e permanecerá invisível. $\gg^{10} \mathrm{E}$, por exemplo ainda, a proposta de que a parede possa ser compreendida como um ser, uma qualquer coisa, um não-sei-quê, pelo qual nos podemos apaixonar (quem diria!?) e que ao mesmo tempo nos possa devorar. ${ }^{11}$ Podendo ser tudo e parecendo não ser nada a que devêssemos dar atenção, a parede contém em si, independentemente das formas que assume no desenho cartográfico da peça, a aprendizagem, a experiência, o conhecimento que Inge e Sylvia

Dactiloscrito, p. 5

10 Idem, ibidem Alusão ao romance de Marlen Haushofer mais uma vez.

11 Idem, ibidem, p. 6. Utilizo nesta passagem a inclusão de um sentido colectivo de recepção extensivel a quem lê e especte considerando que o que é do texto e da cena nos tem como interlocutores directos. não conseguem decifrar, construindo elas por isso com a parede, que também as espelha, uma relação de substância inversa e deformada mas não complementar. A antropofagia quase se consuma e não o amoroso entendimento desejado. Há sangue que baste nesta peça de Jelinek. Quando ele não escorre, pulsa.

\section{ESBOCCO DE UMA CARTOGRAFIA DO SALTO}

Expressa-se deste modo a criação de uma paisagem textual e de considerável interesse cénico derivada de um único foco principal - a parede - como «referencial do nosso projectar e construir territórios» (Turri, 2011: 169). É da mulier figurans que parte o adensamento do objecto sobre o qual a avidez de infinito e de pacificação conduz a linguagem não apenas a dizer coisas, mas também a com elas se fundir.

Em termos e ao modo da paisagem geográfica planeada, que aqui decorre de um amplo arco desenhado entre a ancestralidade grega e a contemporaneidade universal, verificamos que essa opção se produz sob a forma do salto: ora estamos veiculados a rituais de sacrifício e assistimos ao narrar vingativo e mitológico (Hesíodo), ora recuperamos quotidianos domésticos que podiam ser actuais, ora somos confrontados com a verdade de uma decisão (Homero), ora acompanhamos caminhadas montanha acima e montanha abaixo sem específico destino, ora somos entretidos com trivialidades do universo publicitário e básico. Este espectro cobre assim um vasto e complexo território que apela ao imaginário e à força anímica do leitor/espectador, que o fustiga e dele exige elasticidade mental em permanência e que não se coaduna com a visível impossibilidade do descanso, da criação e uso de distância, de um pathos da distância como é referência em Byung-Chul Han (ver epígrafe).

Se quisermos lançar um repto ao emaranhado de situações engendradas em torno da parede nesta peça, poderemos então considerar a possibilidade de caminhar seguindo o desenho de uma cartografia organizada pela autora, de forma sequencial mas também aos saltos e sob o signo da urgência, do princípio ao fim do texto e fora de um critério enumerador pontual que apenas satisfaça o nosso interesse interpretativo.

Se considerarmos esta hipótese, verificaremos que o território a cartografar releva de uma dupla dependência: o próprio espaço (com ou sem detalhes de materialização) e quem sobre ele se debruça. Desta relação lógica, mas não imediatamente perceptível, podemos inferir que as 
imagens produzidas, e que no caso de $A$ Parede resultam da organização de unidades composicionais escritas, se ajustam à ideia de concepção de uma cartografia «sagaz» de paisagem. O termo «sagaz» está associado ao pensamento de Alexander von Humboldt, o qual defendia que o território que se pretende cartografar contém em si «a coisa e a imagem da coisa».12

Partindo do princípio de que a parede adquire uma supra e múltipla representatividade na organização elementar da peça de Jelinek, ela torna-se substância de uma paisagem-teatro (Turri, 2011: 173) que configura ao mesmo tempo a observação/audição/leitura mas igualmente a vontade e o acto de transformar aquilo de que é imagem visível e invisível. Nela habita ainda a potência da criação destrutiva mas reconfiguradora como pertença a uma paisagem com verdade, paisagem feita de ciclicidade e de «eterno retorno».

Na sua essência espectral, a parede concede o alcance do que se destaca na condição veiculadora de conhecimento. Ela torna-se coincidentemente coisa e imagem da coisa. A sua descrição e capacidade de interacção cumprem com a relevância da sua função em cada situação. Ela apresenta-se na maior parte das vezes como um objecto espacial englobado por uma linha de horizonte, mesmo que esta não seja mencionada. A sua condição de integrante principal na geografia do texto atribui-lhe a singularidade de representar tudo o que está vedado a outros eventuais objectos ou ideias de objectos. Ela incorpora em si as leis do acto criador que por certo ignoramos na sua gestação própria, mas que não ignoramos enquanto esboço, traço, desenho de linhas cruzadas que provêm de todas as direcções exteriores às vozes e aos seus ecos. Ela abarca em si o espelhamento do que é vivo e morto, do que é a nossa perturbação em busca de descanso e silêncio.

Mortal é o salto que as desfiguradas ${ }^{13}$ Inge e Sylvia ensaiam em busca de verdade e de conhecimento enquanto escolhem como baixela loiça

2 Gerhard Hard, Der 'Totalcharakter der Landschaft'. Re-Interpretation einiger Textstellen bei Alexander von Humboldt, in Erdkundliches Wissen, Beiheft, Wiesbaden, 1970, pp. 49-71.

13 Utilizo neste caso a desfiguração como modo de co-responsabilidade nas muitas formas de aparência e representação da parede associadas a combinatórias de cariz sexual e mítico-históricas. A este panorama pertence, por razão óbvia, a mulier figurans como capacidade e expressão observadora, contemplativa, reflexiva e inquiridora que, associada à mulier faber, invoca a terceira figura enunciada como Therese/Marlen/Tirésias-mulher. Recupera-se nesta enunciação a grega lateral a metamorfose de Tirésias em mulher, após ter morto uma cobra-fêmea que copulava com o seu parceiro. Regressa Tirésias ao seu género anterior quando, repetido o episódio alguns anos depois, é a cobra-macho que é alvo de despedaçamento. Tirésias no Monte Citéron, alguns anos depois, é a cobra-macho que é alvo de despedaçamento. Tirésias no Monte Citéron, por isso fundador da mitologia grega. Mais se pode acrescentar terem por lá andado Édipo, Acteon e Penteu, mas por lá se fizeram também batalhas entre Tebas e Atenas. Muito se despedaçou e muitos foram os restos que a nossa memória colectiva guardou. miniatural, talvez feita de plástico e própria para brincar aos jantarinhos. Dessa refeição não comerá Therese por si mas como simulacro e simulação de um transfigurado Tirésias, que lhe empresta sabedoria e a faz repetir o seu enigma. Quem será afinal o enfaixado ou antes a enfaixada? Tirésias/Therese, seres fictícios e transmutáveis. De quem são as artes da palavra enigmática? A actividade pensativa é perigosa e pode ter limite interno.

Entretanto, as caixas com o sangue do bode estão a abarrotar com o alimento. «De repente deixamos de descer a escada com a nossa refeição, porque estamos a escalar a parede que não tínhamos visto.. ${ }^{14}$ As duas caminhantes tornaram-se por fim escaladoras. Para isso servem as botas calçadas no início do primeiro acto. Agora retorna o tema de Ulisses em escuta e à entrada do Hades. A parede troca favores com o rochedo no alto do qual se encontram as desfiguradas, arfantes pela altitude, desajeitadas porque entornam o sangue, parecem esgotados os argumentos. Para onde saltar, i. e., para onde ir? O que haverá que um salto não possa resolver depois de entornado o sangue? Sylvia e Inge não se remetem ainda ao silêncio porque prestam atenção ao que lhes foi dito e ao que escutarão «num rádio portátil antigo» e através de voz masculina. Voltamos agora, através da mediação radiofónica, a um intervalo, um salto na relação entre espaço e tempo, e na companhia de Homero. As palavras da Odisseia regressam como um eco e sem que estejam agarradas a um corpo visível. Não é do cego Tirésias ou da sua sucessora que elas provêm, mas de uma voz que faz leitura ansiosa e manipuladora dos ouvintes ao narrar versão livre e com proximidade a partes do Canto XI já identificadas. ${ }^{15}$

Permanecemos no âmbito da geografia antiga com palavras no feminino que nos chegam agora ipsis verbis da Teogonia, de Hesíodo. Fecha-se o circuito iniciado no primeiro acto: a espiral de violência antes anunciada e mostrada, a criação associada a destruição invocam o insondável regresso do mesmo.

O supremo progresso do conhecimento provém, quem sabe, da intensificação dos gestos mais vulgares: tomar entre mãos, subir e descer os degraus de uma parede, espreitar por uma porta entreaberta. Talvez, para conhecermos os humanos, precisemos de os isolar. Do alto do rochedo avista-se o abismo próprio do indeterminado, a ampla paisagem

14 Dactiloscrito, p. 27.

15 Homero, Odisseia, trad. Frederico Lourenço, Lisboa, Livros Cotovia, 2003, p. 182. 
que funde todas as coisas pesadas, sujeitas a nascer e a perecer num magma de energia pura. Busquemos silêncio e descanso.

Este texto é uma homenagem às mulheres e escritoras Marlen Haushofer, Sylvia Plath e Ingeborg Bachmann. Com Elfriede Jelinek, aprendi uma vez mais a reconhecer, por direito de transmissão, o que a vida segrega e deixa cair como imagens e modos de associação, o que é apropriação, o que é transfiguração, aquilo que sempre podemos perder e ganhar no imediato que é a vida.

\section{REFERÊNCIAS BIBLIOGRÁFICAS}

HAN, Byung-Chul (2016), No Enxame-Reflexões sobre o digital, Lisboa, Relógio D’Água.

HARD, Gerhard (1970), Der 'Totalcharakter der Landschaft'. Re-Interpretation einiger Textstellen bei Alexander von Humboldt, in Erdkundliches Wissen, Beiheft, Wiesbaden.

HEsíodo (2014), Teogonia Trabalhos e Dias, pref. Maria Helena Rocha Pereira, introd., trad. e notas de Ana Elias Pinheiro e José Ribeiro Ferreira, Lisboa, Imprensa Nacional-Casa da Moeda, prefácio disponível em https://www.incm.pt/portal/bo/produtos/anexos/10262320141222122405436.pdf.

Hомеro (2003), Odisseia, trad. Frederico Lourenço, Lisboa, Livros Cotovia.

JELINEK, Elfriede - (2019), A Morte e a Donzela - Dramas de Princesas, tradução e nota introdutória Onde começam e acabam as princesas?, de Anabela Mendes, Lisboa, teodolito/edições afrontamento.

- (2018), A Morte e a Donzela - Dramas de Princesas, tradução e nota introdutória - Onde começa e acaba uma princesa?, de Anabela Mendes, Lisboa, Artes \& Engenhos (edição de 25 exemplares numerados).

- (2003), Der Tod und das Mädchen I-V-Prinzessinnendramen, Bloomsbury Taschenbuch, Goldmann Verlag, 2003. [A edição consultada deixou de se publicar nesta editora embora continue a ser vendida pela Amazon.] - (s/d), Homepage, https://www.elfriedejelinek.com/.

JÜRS-MUNBY, Karen (2009), The Resistant Text in Postdramatic Theatre: Performing Elfriede Jelinek's Sprachflächen [Superfícies de linguagem], Performance Research: A Journal of the Performing Arts.

KLESSIN GER, Hanna (2006), Postdramatik: Transformationen des epischen Theaters bei Peter Handke, Heiner Müller, Elfriede Jelinek und Rainald Goetz, Berlim/Nova Iorque, Edition De Gruyter.

TURRI, Eugenio (2011), A Paisagem como Teatro-Do território vivido ao território representado, in Adriana Veríssimo Serrão (coord.), Filosofia da paisagem. Uma Antologia, Lisboa, Centro de Filosofia da Universidade de Lisboa.

\section{ANABELA MENDES}

-

Germanista e professora na Faculdade de Letras da Universidade de Lisboa. A partir de 2018, tornou-se investigadora independente. Desenvolve a sua actividade científica e ensaística nas áreas dos Estudos de Expressão Alemã, Estética e Filosofia da Arte, Ciência e Arte, Teoria e Dramaturgia Radiofónica, Artes Performativas, Viagens de Longo Curso. Mantém desde 2019 um projecto, com outros investigadores, dedicado ao estudo das artes no arquipélago dos Bijagós (Guiné-Bissau) intitulado «Bijagós: Uma etnia de viver homeostático». 